Thorax (1969), 24, 353.

\title{
Pulmonary reaction to Hytrast
}

\author{
A. R. MOR LEY \\ From the Department of Pathology, The Royal Victoria Infirmary, University of Newcastle upon Tyne
}

\begin{abstract}
Hytrast, a new bronchographic medium of high iodine content, provides excellent radiographic contrast. A number of clinical, pathological, and experimental studies have revealed inflammatory changes after pulmonary retention of Hytrast. Examination of 43 unselected pneumonectomy specimens after Hytrast bronchography revealed typical crystals in 15 instances. The pulmonary reaction included macrophage and foreign body giant cell accumulation, neutrophil leucocyte exudation, and fibrosis within terminal bronchioles and alveoli. It was concluded that these changes were associated with Hytrast retention.
\end{abstract}

The gradual refinement of bronchographic contrast media has been reviewed by Le Roux and Duncan (1964). Iodized poppy seed oil (Lipiodol) has been used since 1922 (Sicard and Forestier, 1922). The addition of sulphanilamide (Visciodol) increased viscosity and reduced alveolar filling, but the occasional complications of methaemoglobinaemia, allergic sensitization, and acute nephritis stimulated the search for a better preparation. In 1953 propyliodone in aqueous solution (Dionosil aqueous) became available but was found to be a mucosal irritant, an objection which suspension in an oily medium (Dionosil oily) overcame.

Hytrast, introduced as a bronchographic medium in 1962, is a neutral suspension of crystals of $N$ (propyl-2 : 3-diol)-3 : 5 diiodo-4-pyridone, and $3: 5$ diiodo-4 pyridone in a hypertonic aqueous solution of sodium carboxymethylcellulose. The latter compound was introduced to maintain the viscosity at $2 \cdot 4-2 \cdot 8$ poise and the $p \mathrm{H}$ at $7 \cdot 1$. The crystals are 2-5 microns across (Le Roux and Duncan, 1964). Esteric groups are not present and hydrolysis to irritant acidic groups does not occur. The concentration of iodine is higher than in previous contrast media $(0.5 \mathrm{~g} . / \mathrm{ml}$. in Hytrast, $0.28 \mathrm{~g} . / \mathrm{ml}$. in Dionosil). Gildenhorn, Springer, Wang, and Hallett (1962), Le Roux and Duncan (1964), and Webb and Fitts (1963) commented on the high quality of bronchograms obtained with Hytrast and on the low incidence of alveolar filling. None of these authors observed a pulmonary reaction to Hytrast, but it has since become apparent that pathological changes may follow its use. Thirty-eight cases have been reported and a single fatality (Agee and Shires, 1965). The number of lung specimens examined by any one author is small, excluding Nelson,
Christoforidis, and Pratt (1964), who examined 14 specimens, and the cases described were self-selected by clinical or pathological abnormalities attributable to Hytrast. Because these are a selected group, the severity of the pulmonary reaction to Hytrast may not be representative of the 'bronchogram' population as a whole. An unselected series of lobectomy and pneumonectomy specimens in which Hytrast bronchography had previously been performed was therefore examined.

\section{RESULTS}

Forty-three unselected pneumonectomy specimens, excised between July 1966 and March 1967, were available for study.

The differences of the mean times between bronchography and resection are not significant: $P=0 \cdot 20-0 \cdot 10$.

Table I shows that there was no significant difference in the mean times elapsing between bronchography and excision in the group containing Hytrast when compared with the group in

T A B L E I

COMPARISON OF CASES WITH AND WITHOUT HYTRAST

\begin{tabular}{|c|c|c|c|}
\hline & & \multicolumn{2}{|c|}{ Pneumonectomy Specirrens } \\
\hline & & $\begin{array}{c}\text { With } \\
\text { Hytrast }\end{array}$ & $\begin{array}{l}\text { Without } \\
\text { Hytrast }\end{array}$ \\
\hline No. of cases .. & .. & 15 & 28 \\
\hline 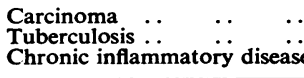 & $\begin{array}{l}\cdots \\
\cdots \\
\cdots\end{array}$ & $\begin{array}{r}10 \\
2 \\
3\end{array}$ & $\begin{array}{r}19 \\
2 \\
7\end{array}$ \\
\hline $\begin{array}{l}\text { Mean time between resecti } \\
\text { bronchography (days) }\end{array}$ & $\begin{array}{l}\text { and } \\
. .\end{array}$ & $7 \cdot 9 \pm 4 \cdot 7$ & $9 \cdot 4 \pm 5 \cdot 6$ \\
\hline
\end{tabular}




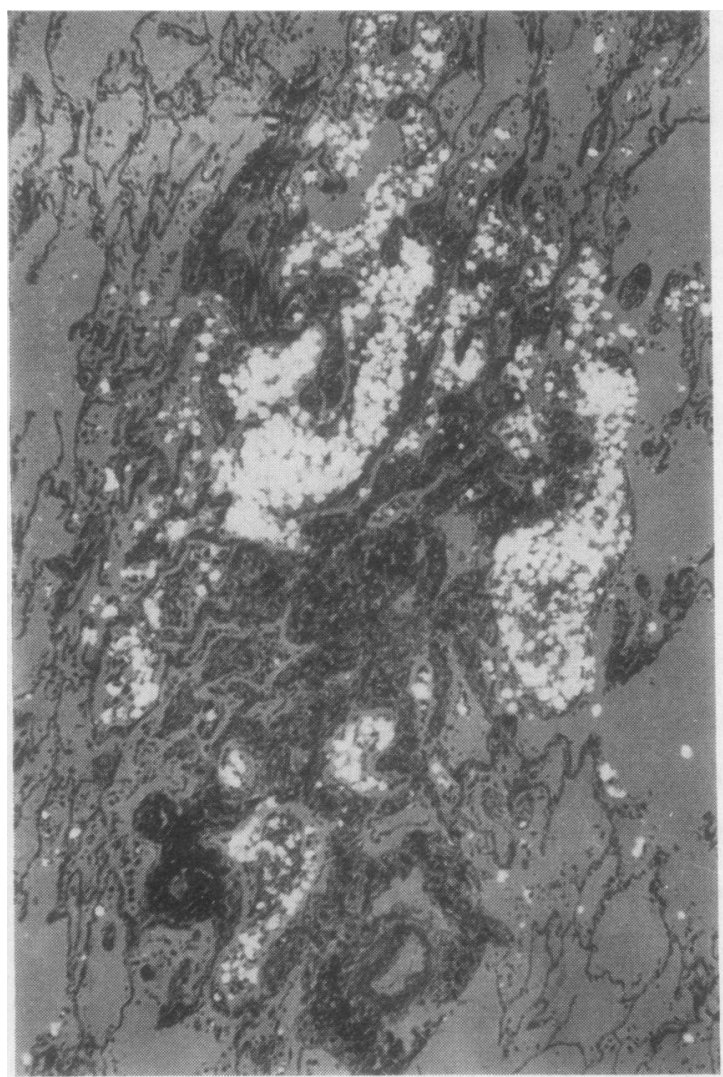

FIG. 1. Intra-alveolar macrophages and Hytrast crystals showing the appearance under polarized light. $H$. and $E$. $\times 50$.

which Hytrast was not found. The spectrum of disease in the two groups was similar.

Under polarized light the irregular crystals of Hytrast were strongly birefringent and showed prominent dichroism. Most crystals were 2-10 microns across, but there were occasional crystals up to 40 microns in diameter. Under ordinary light the crystals had a glassy-green appearance.

\section{PATHOLOGY}

Most Hytrast foci were of microscopic proportions and in only three specimens did yellow-white foci, $2-3 \mathrm{~mm}$. in diameter, attract attention macroscopically. In two cases associated fibrosis was evident.

Histologically crystals were found in alveoli (Fig. 1) in all except one specimen, where they lay within a bronchiectatic abscess cavity. In half of the cases Hytrast was found in bronchi and bronchioles, but never in lymph nodes (Table II).
T A B L E I I

DISTRIBUTION AND REACTION TO HYTRAST CRYSTALS

\begin{tabular}{|c|c|c|c|c|}
\hline State of Hytrast & .. & .. & $\begin{array}{l}\text { Free } \\
\text { Macrophages } \\
\text { Giant cells }\end{array}$ & $\begin{array}{r}13 \\
15 \\
9\end{array}$ \\
\hline Location of Hytrast. . & .. & .. & $\begin{array}{l}\text { Bronchial tree } \\
\text { Alveoli } \\
\text { Interstitial }^{1} \\
\text { Lymph nodes }^{-}\end{array}$ & $\begin{array}{r}8 \\
14 \\
5 \\
0\end{array}$ \\
\hline Associated reaction & . & .. & $\begin{array}{l}\text { Neutrophils } \\
\text { Fibrosis }\end{array}$ & $\begin{array}{l}7 \\
3\end{array}$ \\
\hline Total number of speci & & $\cdots$ & . & 15 \\
\hline
\end{tabular}

${ }^{1}$ Small numbers of crystals free or in macrophages.

In all specimens most of the Hytrast had been ingested by macrophages, but nearly all cases showed some free crystals (Fig. 2). Usually a mass of crystal-bearing macrophages filled the whole of an alveolus, and sometimes the alveolar lining cells were cuboidal. Most macrophages contained several crystals, and often carbon or iron particles as well. Small and large giant cells were frequently seen, some developing within two days of bronchography (Fig. 3). Hytrast was on occasions associated with intra-alveolar granular eosinophilic

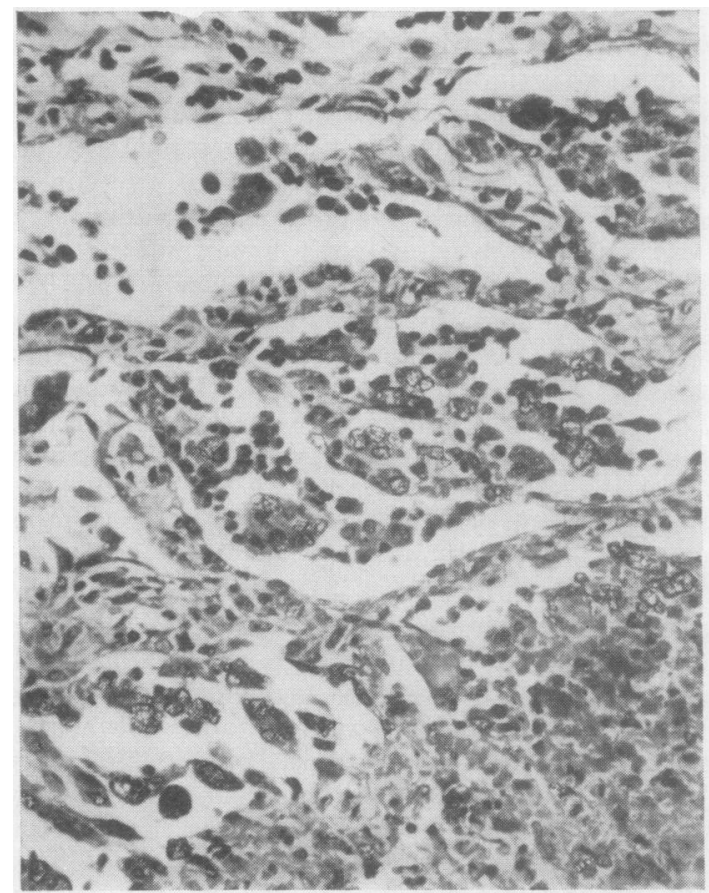

FIG. 2. Hytrast in macrophages and associated with neutrophil leucocytes; gran:lar debris is also present. $H$. and $E . \times 340$.

.




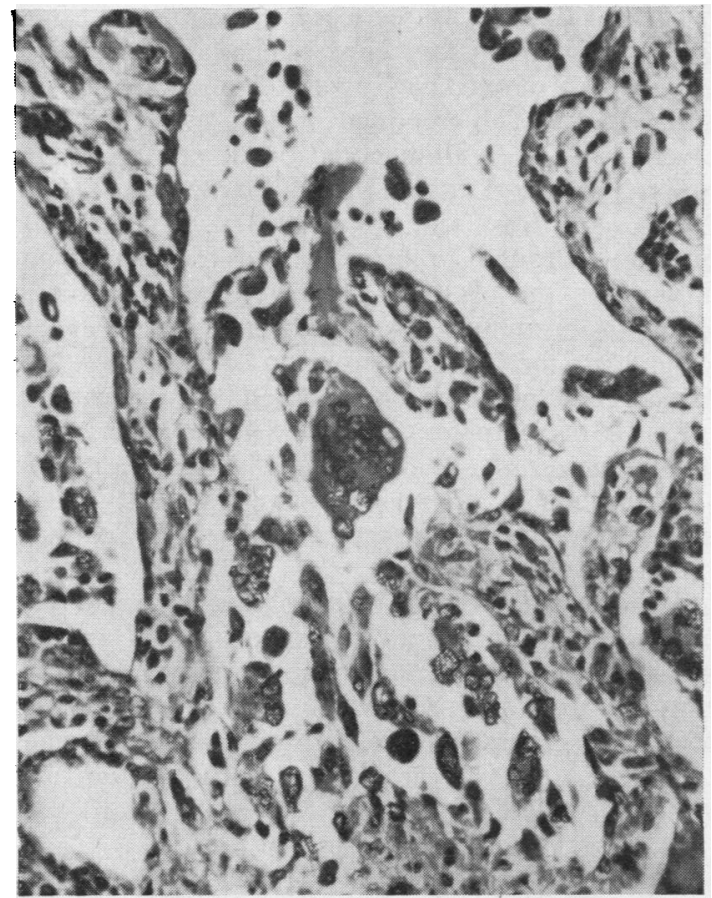

FIG. 3. Hytrast crystals free, in macrophages, and in a multinucleate giant cell. $H$. and $E . \times 340$.

debris, which appeared to be the remains of degenerate macrophages (Fig. 2).

In eight specimens Hytrast was present in the bronchial passages (Fig. 4) and in five cases the epithelium was intact. On one occasion Hytrast was found in a bronchiectatic area with much acute inflammatory cell infiltration. Thus in only two of the eight specimens was there evidence that Hytrast had damaged the bronchiolar epithelium.

In seven cases Hytrast was associated with neutrophils (Fig. 2), and in four the focus of Hytrast was related to carcinoma, bronchiectasis, or a mycetoma. It seems unreasonable in these cases to ascribe the inflammatory cell infiltrate to the bronchographic medium. However, in three specimens with carcinoma of the lung, alveolar tissue adjacent to the Hytrast focus was normal or showed centrilobular emphysema, yet Hytrast was closely associated with neutrophil leucocytes. It therefore seems that Hytrast may cause an acute inflammatory cell response.

The difficulties of attributing a neutrophil leucocyte response to Hytrast accumulations also apply to the fibrosis which is sometimes associated. In two specimens Hytrast crystals were enveloped and infiltrated by fibrocytes and reticulin fibres in such profusion - and with the fibrous tissue reaction clearly confined to the focus of crystals - that there seems little doubt that Hytrast can induce fibrosis (Fig. 5). The shortest interval between bronchography and the development of fibrosis was seven days. In one case fibrosis had occurred within alveoli (Fig. 6), and in the second fibrosis in terminal bronchioles led to the development of obstructive fibrous plugs (Fig. 7). Hytrast with a fibrous tissue reaction occurred in relation to a bronchiectatic abscess, but Hytrast cannot be regarded as the cause of the acute inflammatory reaction.

\section{DISCUSSION}

Alveolar filling is not common using Hytrast (Le Roux and Duncan, 1964 ; Webb and Fitts, 1963 ; and Wright, 1965) but was found to be more common than with Dionosil oily (Cabrera, Pickren, and Sheehan, 1967). There is a direct relation between the alveolar filling and the viscosity of the bronchographic medium. There is

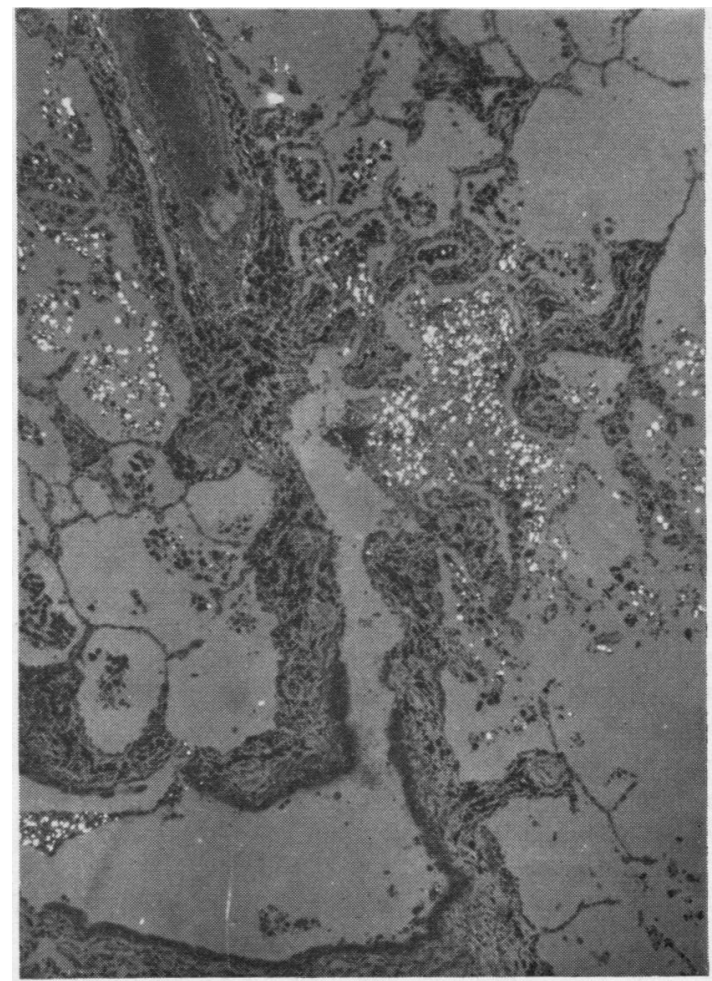

FIG. 4. Intra-alveolar and bronchiolar Hytrast under polarized light. $H$. and $E . \times 45$. 


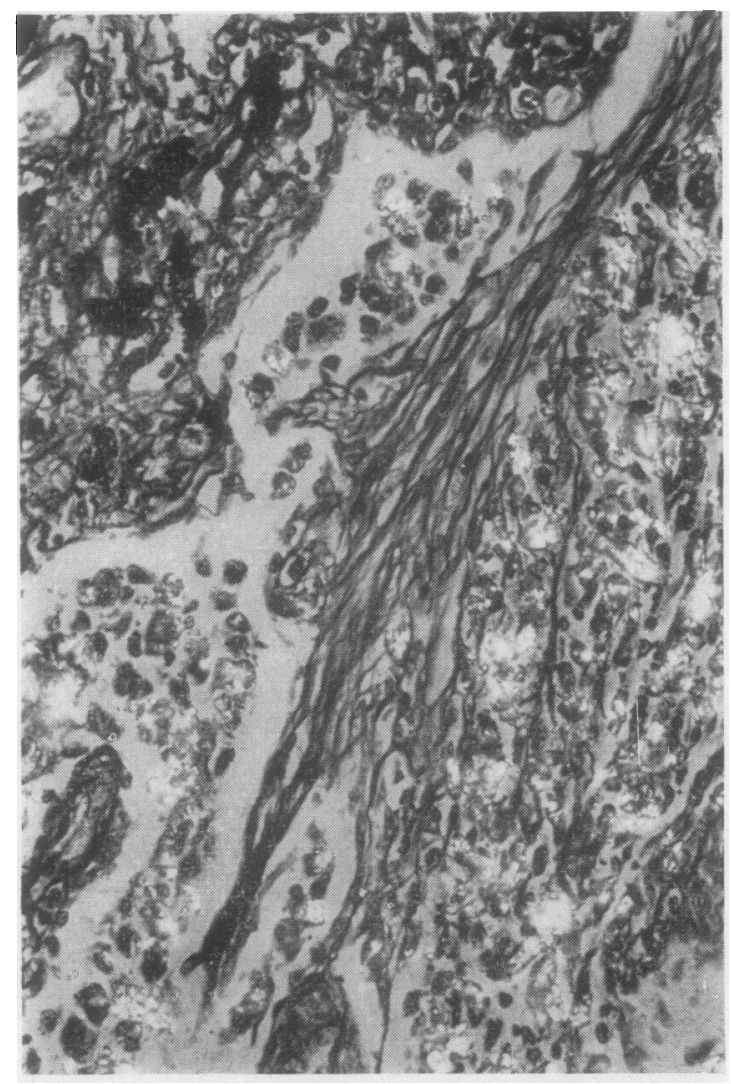

FIG. 5. Hytrast crystals enveloped by reticulin fibres. Foots' reticulin stain $\times 500$ with polarized light.

little difference between the viscosity of Hytrast and that of other bronchographic media, but dilution with water is easily performed and may be necessary for optimal contrast (Le Roux and Duncan, 1964). Lang (1964) was unable to correlate the extent of alveolar filling and the development of post-bronchographic pyrexia. Pyrexia occurred in $16-28 \%$ of cases in which Hytrast or Dionosil oily were used (Gildenhorn et al., 1962 ; Le Roux and Duncan, 1964 ; Light and Oster, 1964 ; Mounts and Molnar, 1962); however, Misener, Quinlan, and Hiltz (1965) observed pyrexia in $66 \%$ of their patients after Hytrast compared with $16 \%$ after Dionosil oily.

Removal of Hytrast from the lung is via the bronchial tree. There is no evidence that Hytrast undergoes enzymatic degradation or is removed through the lymphatics, hence the excretion of Hytrast even more than of Dionosil or Lipiodol is dependent on efficient bronchial removal. Hytrast tends to accumulate around areas of bronchial damage (Greenberg, Hallam, and Spjut, 1964a), probably a consequence of impaired elimination of particles by the bronchial mucosa. When Hytrast is retained it lies mainly in the alveoli, an observation noted by others (Agee and Shires, 1965 ; Dutra, 1964 ; Greenberg et al., 1964b ; and Rayl and Spjut, 1963). Less frequently, Hytrast is found in bronchi and terminal bronchioles. In the present study Hytrast retention in areas of bronchiectasis has been noted. Particle size affects the bronchial removal of particles. The largest crystals seen have been more than 40 microns in diameter, confirming the observation of Misener et al. (1965), who found particles up to 100 microns in diameter. Histologically the particles measured appeared to be single crystals rather than aggregations.

Following alveolar retention a characteristic cellular reaction ensues. This consists of macrophages, multinucleate giant cells, neutrophil infiltration, bronchiolitis, and fibrosis. This reaction has been seen in the present and previous studies (de Bruin, 1965; Greenberg et al., 1964a; Light and

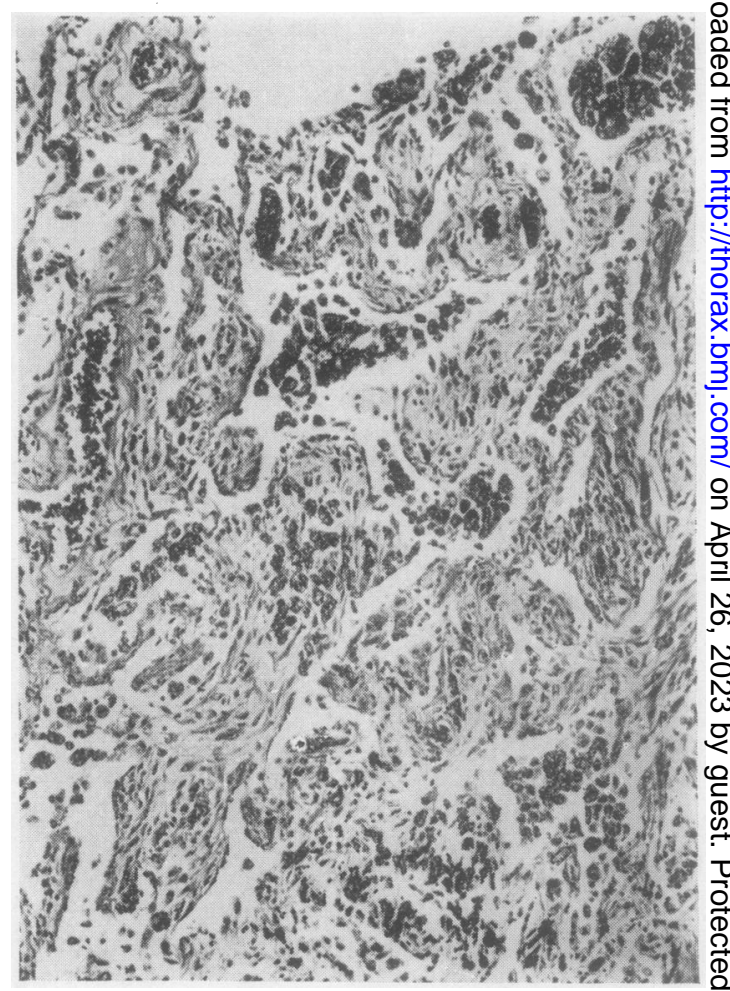

FIG. 6. Organizing bronchopneumonia with Hytrast crystals enveloped in fibrous tissue. $\mathrm{H}$. and $\mathrm{E} . \times 110$. $\vec{\omega}$ $\stackrel{\vec{x}}{\vec{P}}$ in 운 $-$

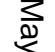
$\overrightarrow{0}$

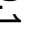
$\omega$ w $\omega$ $\overrightarrow{6}$ 8 


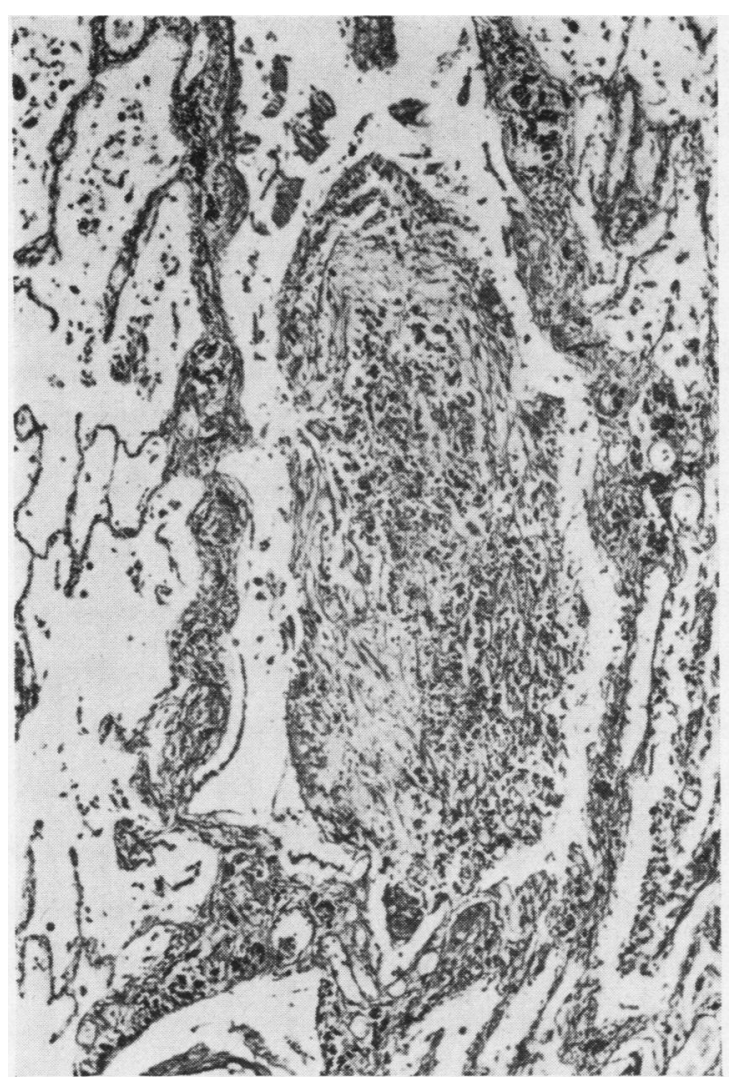

FIG. 7. Fibrous plug within terminal bronchiole containing Hytrast. Foots' reticulin stain $\times 125$.

Oster, 1964 ; and Misener et al., 1965). The sequence of changes is not easily followed in surgical specimens, which are usually complicated by other pathological features. Under controlled experimental conditions the sequence of cellular and tissue changes after Hytrast exposure can be followed. Although species differences may occur the changes observed experimentally are similar to those seen in surgical specimens. Greenberg, Spjut, and Hallman (1966) isolated the upper lobe of the dog lung by ligation and studied the pulmonary reactions after exposure of the isolated lobe to aqueous and oily Dionosil, iodized oil, and Hytrast. Within 24 hours Hytrast induced a neutrophil leucocyte response and an acute bronchiolitis. At 10 days a fibrosing bronchiolitis was present, and chronic granulomatous inflammation persisted for 30 days after exposure. In all lungs exposed to Hytrast large numbers of giant cells developed. Light and Oster (1964) injected Hytrast into the rabbit bronchial tree without ligation of the regional bronchus. An acute inflammatory response preceded the ingestion of Hytrast by macrophages and the formation of foreign body giant cells. In this study Hytrast crystals were seen within lymphatic channels, but this observation remains unconfirmed. Sixty days after administration all Hytrast had disappeared without residual fibrosis. Rayl and Spjut (1963) and Nelson et al. (1964) reported similar findings.

The present study shows that pulmonary tissue changes may occur without the development of a clinically apparent reaction. The finding of Hytrast retention in 15 out of 43 cases submitted to Hytrast bronchography is probably an underestimate as the study was retrospective and normal areas were not routinely sampled. Nelson et al. (1964) observed changes attributable to Hytrast in 11 out of 14 cases one to five days after bronchography. Light and Oster (1964) found Hytrast in four of 15 surgical specimens. In contrast, Webb and Fitts (1963) found no changes in 23 specimens, and Le Roux and Duncan (1964) found no changes attributable to Hytrast in four specimens.

In addition to radio-opaque orystals, Hytrast also contains carboxymethyl cellulose. De Bruin (1965) noted the presence of intra-alveolar basophilic material which was thought to be carboxymethyl cellulose, and which stained metachromatically with toluidine blue. Leopold and Seal (1961) considered the possibility that carboxymethyl cellulose may have been responsible for the tissue reaction following Dionosil bronchography. They demonstrated material which stained negatively with Schiff's reagent and positively with Alcian blue, but which was not metachromatic with tartaric acid-thionine. Whether this material was carboxymethyl cellulose is doubtful since the latter is water soluble and would probably have been removed by processing in aqueous reagents. The role of carboxymethyl cellulose in the pulmonary reaction to bronchographic media remains uncertain.

Thanks are due to Mr. W. Barnsley, Mr. A. Blesovsky, and Dr. J. Miller for discussion and access to clinical reports. The advice and encouragement of Professor A. G. Heppleston is gratefully acknowledged. The technical assistance of Mr. J. McLennan and the photographic work of Mr. W. Robinson have been of the greatest possible value. Miss M. King, of the Newcastle upon Tyne University Library, has given invaluable bibliographical assistance.

\section{REFERENCES}

Agee, O. F., and Shires, D. L. (1965). Death after bronchography with a water-soluble iodine-containing medium. J. Amer. med. Ass., 194, 459.

de Bruin, C. D. (1965). Complications following bronchography with Hytrast (in Dutch). Ned. T. Geneesk, 109, 758. 
Cabrera, A., Pickren, J. W., and Sheehan, R. (1967). Crystalline inclusion pneumonia following the use of Hytrast in bronchography. Amer. J. clin. Path., 47, 154.

Dutra, F. R. (1964). Crystalline bronchographic medium in pulmonary tissue. Ibid., 41, 49.

Gildenhorn, H. L., Springer, E. B., Wang, S. K., and Hallett, W. Y. (1962). Evaluation of a new contrast medium for bronchography. Dis. Chest, 42, 596.

Greenberg, S. D., Hallman, G. L., and Spjut, H. J. (1964a). Pulmonary tissue reaction following Hytrast bronchograms. Ann. Otol. (St. Louis), 73, 1095.

(1964b). Pulmonary tissue reaction following Hytrast bronchograms. Trans. Amer. broncho-esoph. Ass., 44, 106.

Spjut, H. L., and Hallman, G. L. (1966). Experimental study of bronchographic media on lung. Arch. Otolaryng., 83, 276.

Lang, E. K. (1964). A comparative study of febrile reactions to Hytrast, aqueous Dionosil, and oily Dionosil in bronchography. Radiology, 83, 455 .

Leopold, J. G., and Seal, R. M. (1961). The bronchographic appearance of "peripheral pooling" attributed to the filling of centrilobular emphysematous spaces. Thorax, 16, 70 .
Le Roux, B. T., and Duncan, J. G. (1964). Bronchography with Hytrast. Thorax, 19, 37.

Light, J. P., and Oster, W. F. (1964). A study of the clinical and pathologic reaction to the bronchographic agent Hytrast. Amer. J. Roentgenol., 92, 615.

Misener, F. J., Quinlan, J. J., and Hiltz, J. E. (1965). Hytrast: a new contrast medium for bronchography. Canad. med. Ass. J., 92, 607.

Mounts, R. J., and Molnar, W. (1962). The clinical evaluation of a new bronchographic contrast medium. Radiology, 78, 231.

Nelson, S. W., Christoforidis, A. J., and Pratt, P. C. (1964). Further experience with barium sulfate as a bronchographic contrast medium. Amer. J. Roentgenol., 92, 595.

Rayl, D. F., and Spjut, H. J. (1963). Bronchographic crystallineinclusion pneumonia due to Hytrast. Radiology, 80, 588 .

Sicard, J. A., and Forestier, J. (1922). Méthode générale d'exploration radiologique par l'huile iodée (lipiodol). Bull. Soc. méd. Hôp. Paris, 3 ser, 46, 463.

Webb, W. R., and Fitts, C. T. (1963). Evaluation of Hytrast as a bronchographic medium. Amer. Surgn, 29, 491.

Wright, F. W. (1965). Bronchography with Hytrast. Brit. J. Radiol., 38, 791 . 